\title{
Cytogenetics of Cucumis L. \\ IV. Comparative study of natural and induced polyploids
}

\author{
A. K. Singh ${ }^{1}$ and K. S. Yadav \\ Cytogenetics Laboratory, Department of Botany \\ University of Jodhpur, Jodhpur 342001, India
}

Received January 10, 1983

The phenomenon of polyploidy has been recognized as one of the most outstanding features in evolution of plants (Stebbins 1971, Jackson 1976) and has also been exploited in crop improvement through polyploid breeding (Müntzing 1951, Randolf 1932). In Cucurbitaceae success of ployploidy has been debated both from evolutionary and agronomic points of view. Recent reports in this family on a number of genera with polyploid forms, Trichosanthes, Melothria, Momordica, and Cucumis (Singh 1974, Singh and Roy 1979, Roy et al. 1966, Agrawal et al. 1976, Shimotsuma 1965, Dane and Tsuchiya 1979), on success of polyploids in Citrullus vulgaris (Kihara 1951, Andrus et al. 1971), and on positive response to polyploid induction for fruit character in Luffa and Cucumis (Roy and Ghosh 1971, Singh and Roy 1975) do not support the old generalization on the role of polyploidy in speciation and in breeding in Cucurbitaceae (Singh 1979) and thus have generated new interest.

The present communication discusses cytogenetic behaviour of four natural polyploid taxa of Cucumis $(2 \mathrm{n}=48), C$. pustulatus, C. membranifolius, C. meeusei and $C$. heptadactylis, and of two colchiploids of $C$. melo var. momordica and $C$. prophetarum with a view to understand the polyploidy in them and cytological stability and agronomic potential of the induced polyploids.

\section{Materials and methods}

Identities and sources of the taxa investigated are listed in Table 1.

Healthy seeds of $C$. melo var. momordica and C. prophetarum were used for colchicine treatment. Three concentrations of colchicine, $0.2 \%, 0.3 \%$, and $0.4 \%$ were applied in three different ways:

\section{a) Apical bud treatment}

A small cotton web soaked in aqueous colchicine solution of a concentration was kept on exposed apical buds of young seedlings for different durations spread over to $2-3$ days between 6.10 a.m. to 2.30 p.m. in order to synchronise the treatment with division cycle (Table 2). Cotton was constantly kept wet by dropping the solution at frequent intervals. At the end of the treatment, the apical buds

I Cytogeneticist, Groundnut Improvement Program, ICRISAT, Patancheru P.O. 502 324, A.P., India. 
were washed thoroughly with water.

\section{b) Seed treatment}

Seeds soaked on moist filter paper for 12 hours, wiped between the folds of blotting paper were immersed in colchicine solution of different concentrations between $6.30 \mathrm{a} . \mathrm{m}$. to $2.30 \mathrm{p} . \mathrm{m}$. for different periods (Table 2). Treated seeds were washed in running water for half an hour and sown in pots.

\section{c) Seedling treatment}

The cotyledonary leaves of young seedlings were immersed in different concenttations of aqueous colchicine solution. The roots were kept wet by wrapping them in moist cotton. After a thorough wash, seedlings were planted in pots. In C. prophetarum this treatment was followed by apical bud treatment (Table 2).

All the secondary shoot arising from treated plants were removed, so as to boost the growth of the treated shoot and to ensure higher ploidy level.

Table 1. Identity and source of Cucumis Species

\begin{tabular}{lccc}
\hline \multicolumn{1}{c}{ Name } & 2n & PI Number & Source \\
\hline $\begin{array}{l}\text { C. pustulatus Hook. F. } \\
\text { (syn. C. aculeatus Cogn.) }\end{array}$ & 48 & 273649 & Georgia, U.S.A. \\
C. membranifolius & 48 & 273571 & \\
C. meeusei & 48 & 376068 & $" \prime$ \\
C. heptadactylis & 48 & 282446 & $"$ " \\
C. prophetarum & 24 & & Jodhpur, India \\
C. melo var. momordica & 24 & & " " \\
\hline
\end{tabular}

For meiotic analysis young flower buds were fixed in acetic alcohol $(1: 3)$ between $7.00 \mathrm{a} . \mathrm{m}$. to $18.30 \mathrm{a} . \mathrm{m}$. A few drops of $5 \%$ ferric chloride were added to the fixative. Anthers were squashed in $1 \%$ acetocarmine. Temporary preparations were used for detailed meiotic analysis and photography. Slides were made permanent by n-butylalcohol schedule (Celarier 1956).

\section{Results}

Table 2 shows that colchicine was most effective at $0.3 \%$ or $0.4 \%$ and also that treatment of apical buds was better than any other.

\section{Morphology}

Morphologically as well as anatomically both the colchiploids were vigorous in leaf, flower, fruit and the seed sizes compared to their respective diploid counterparts (Figs. la, b, c, d, e, f). Stomata size was also large but the number per unit area was reduced. Similarly the seed size were larger, although number of seeds per fruit was less (Table 3). A comparative account of morphological details of diploid species and their respective autotetraploids is summarised in Table 3.

Cytology

At MI both the colchiploids showed univalents and multivalents along with 
normal bivalents (Figs. $1 \mathrm{~g}, \mathrm{~h}$ ). Ranges and means of univalents were $0-4$ and 1.2 , and $0-4$ and 0.88 , respectively in $C$. melo var. momordica and $C$. prophetarum. In natural polyploid taxa, $C$. pustulatus and $C$. membranifolius showed regular bivalents only (Figs. 2a, b) while in $C$. meeusei and $C$. heptadactylis occasional quadrivalents (means 0.12 and 0.2 , respectively) were observed (Table 4 , Figs. 2d, 2e).

Table 2. Details of colchicine treatments in Cucumis species

\begin{tabular}{ccccccc}
\hline \hline Species & $\begin{array}{c}\text { No. of } \\
\text { plants } \\
\text { treated }\end{array}$ & $\begin{array}{c}\text { Colchicine } \\
\text { concen- } \\
\text { tration } \\
\%\end{array}$ & $\begin{array}{c}\text { Duration } \\
\text { in hrs. }\end{array}$ & $\begin{array}{c}\text { No. of } \\
\text { surviving } \\
\text { plants }\end{array}$ & $2 \times$ & \multicolumn{1}{c}{$4 \times$} \\
\hline $\begin{array}{c}\text { C. melo var. } \\
\text { momordica }\end{array}$ & 15 & 0.2 & $\begin{array}{l}\text { Seedling treatment } \\
16-18\end{array}$ & 10 & 8 & 2 , mixoploid \\
& 15 & 0.3 & $14-15$ & 9 & 6 & 3 , mixoploid \\
C. prophetarum & 15 & 0.4 & $\begin{array}{l}16-17 \\
\text { Seed treatment }\end{array}$ & 7 & 5 & 2 , tetraploid \\
& 10 & 0.4 & $\begin{array}{l}\text { S hrs. } \\
8 \text { hrs. seed treatment } \\
+8 \text { hrs. seedling } \\
\text { treatment }\end{array}$ & 7 & 6 & 1 , tetraploid \\
\hline
\end{tabular}

Table 3. Comparative morphology of diploids and induced autotetraploids in Cucumis species

\begin{tabular}{|c|c|c|c|c|}
\hline \multirow{2}{*}{$\begin{array}{l}\text { Characters } \\
\text { studied }\end{array}$} & \multicolumn{2}{|c|}{ C. melo var. momordica } & \multicolumn{2}{|c|}{ C. prophetarum } \\
\hline & Diploid & Tetraploid & Diploid & Tetraploid \\
\hline Thickness of stem & $0.3 \mathrm{~cm}$ & $0.4 \mathrm{~cm}$ & $0.2 \mathrm{~cm}$ & $0.3 \mathrm{~cm}$ \\
\hline Length of internode & $8.17 \mathrm{~cm}$ & $6.06 \mathrm{~cm}$ & $4.12 \mathrm{~cm}$ & $5.0 \mathrm{~cm}$ \\
\hline Length of petiole & $7.06 \mathrm{~cm}$ & $7.62 \mathrm{~cm}$ & $5.86 \mathrm{~cm}$ & $6.75 \mathrm{~cm}$ \\
\hline $\begin{array}{l}\text { Length and breadth } \\
\text { of leaf }\end{array}$ & $6.09 \times 7.7 \mathrm{~cm}$ & $6.16 \times 10.36 \mathrm{~cm}$ & $3.8 \times 3.12 \mathrm{~cm}$ & $4.08 \times 5.08 \mathrm{~cm}$ \\
\hline Colour of leaf & Light green & Dark green & Light green & Dark green \\
\hline Length of calyx tube & $0.56 \mathrm{~cm}$ & $0.63 \mathrm{~cm}$ & $0.45 \mathrm{~cm}$ & $0.52 \mathrm{~cm}$ \\
\hline $\begin{array}{l}\text { Length and breadth } \\
\text { of corolla tube }\end{array}$ & $0.47 \times 0.39 \mathrm{~cm}$ & $0.74 \times 0.58 \mathrm{~cm}$ & $0.6 \times 0.55 \mathrm{~cm}$ & $0.8 \times 0.7 \mathrm{~cm}$ \\
\hline Size of fruit & $3.4 \times 3.2 \mathrm{~cm}$ & $3.8 \times 3.5 \mathrm{~cm}$ & $3.9 \times 2.5 \mathrm{~cm}$ & $4.2 \times 2.5 \mathrm{~cm}$ \\
\hline No. of seeds/fruit & 180 & $85^{*}$ & 120 & $15^{*}$ \\
\hline Seed size & $4.2 \times 2.5 \mathrm{~mm}$ & $6.0 \times 2.83 \mathrm{~mm}$ & $4.34 \times 2.14 \mathrm{~mm}$ & $4.85 \times 2.5 \mathrm{~mm}$ \\
\hline No. of stomata/field & $10.8(10 \times 45)$ & $6.4(10 \times 45)$ & $11(10 \times 45)$ & $6.7(10 \times 45)$ \\
\hline $\begin{array}{l}\text { Length and breadth of } \\
\text { guard cells }\end{array}$ & $4.5 \times 1.1$ & $4.83 \times 1.25$ & $3.8 \times 0.8$ & $4.22 \times 1.1$ \\
\hline $\begin{array}{l}\text { Length and breadth of } \\
\text { stomatal aperture }\end{array}$ & $3.2 \times 0.95$ & $3.5 \times 1.16$ & $3.5 \times 0.8$ & $4.0 \times 1.05$ \\
\hline Pollen size & $3.75 \mu \mathrm{m}$ & $4.38 \mu \mathrm{m}$ & $2.38 \mu \mathrm{m}$ & $3.0 \mu \mathrm{m}$ \\
\hline
\end{tabular}

* Including shrivelled seeds.

The mean chiasma frequency was almost identical in all the four natural polyploids. The details of chromosome associations are summarised in Table 4.

At AI both the colchiploids have almost similar percentages of PMCs with regular distribution of chromosomes ( 48 and 50 ) and high pollen fertility $(76 \%$ and 


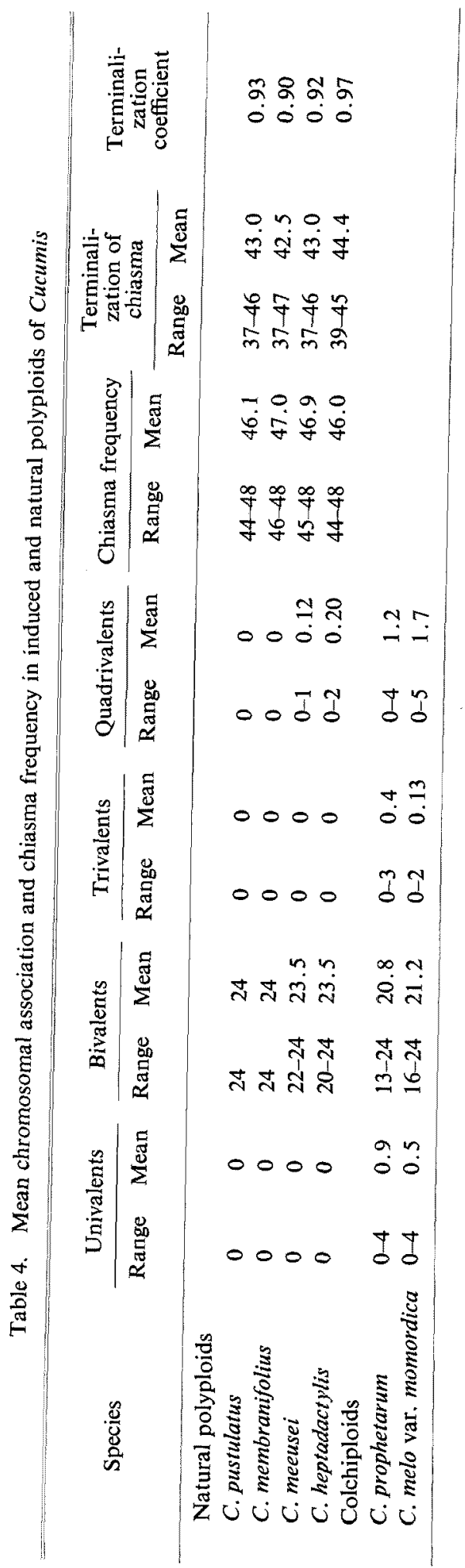




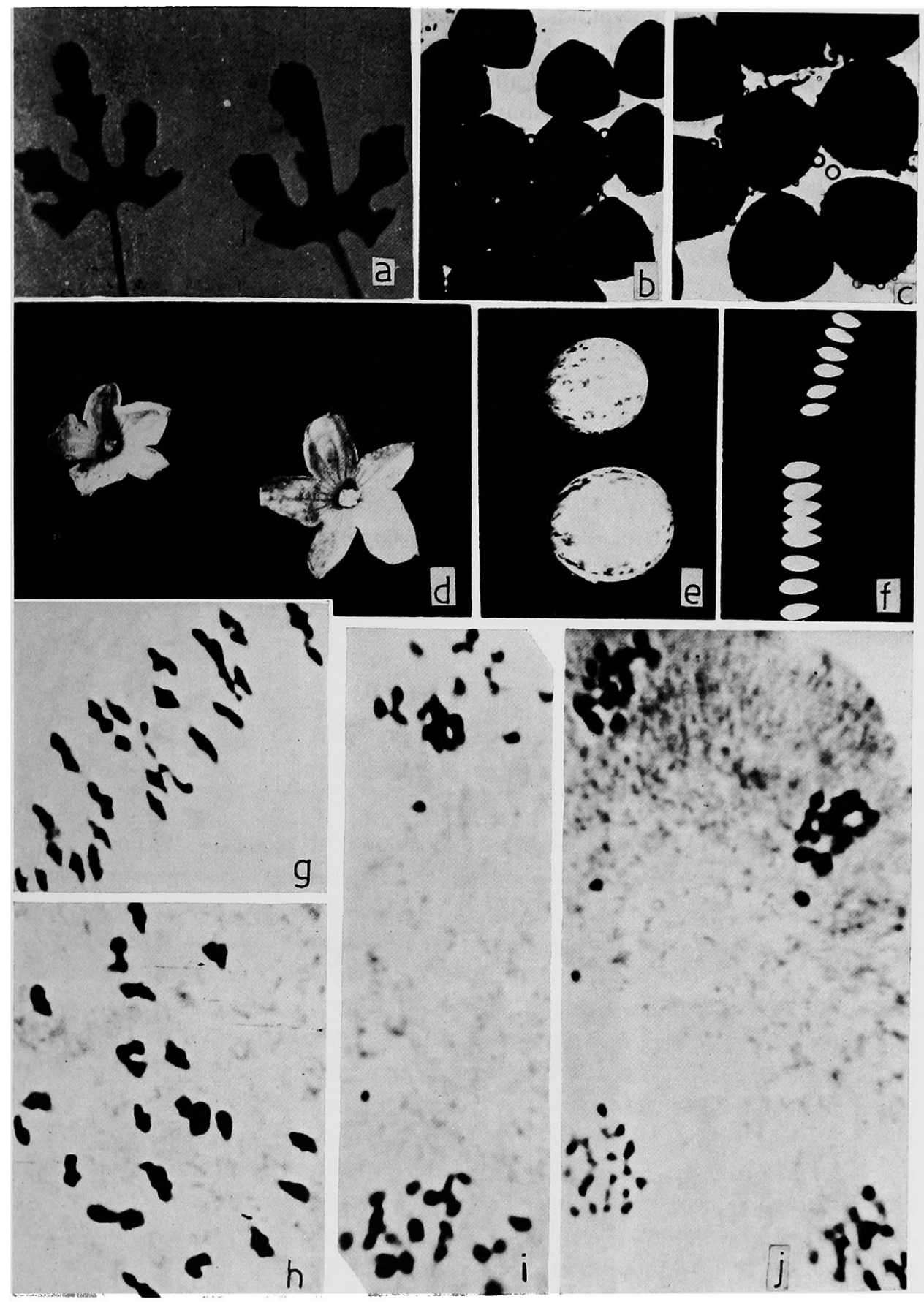

Figs. 1a-j. a, leaves of $C$. prophetarum, diploid left and tetraploid right; $C$. melo var. momordica. b, diploid pollen. c, tetraploid pollen. d, diploid flower left and tetraploid right. e, diploid fruits up and tetraploid down. f, diploid seeds up and tetraploid down. Pollen mother cells of tetraploid $C$. prophetarum showing: g, 24 II. h, $20 \mathrm{II}+2 \mathrm{IV}$ at MI. i, and j, laggards at $\mathrm{AI}$ and 
$77 \%$ ). Among natural polyploids, C. pustulatus and C. membranifolius have normal distribution of chromosomes, and high pollen fertility, (75 and $78 \%$, respectively), while in two other taxa, C. meeuse and C. heptadactylis, $30 \%$ and $20 \%$ of PMCs respectively, showed irregular distribution of chromosomes in the form of laggards

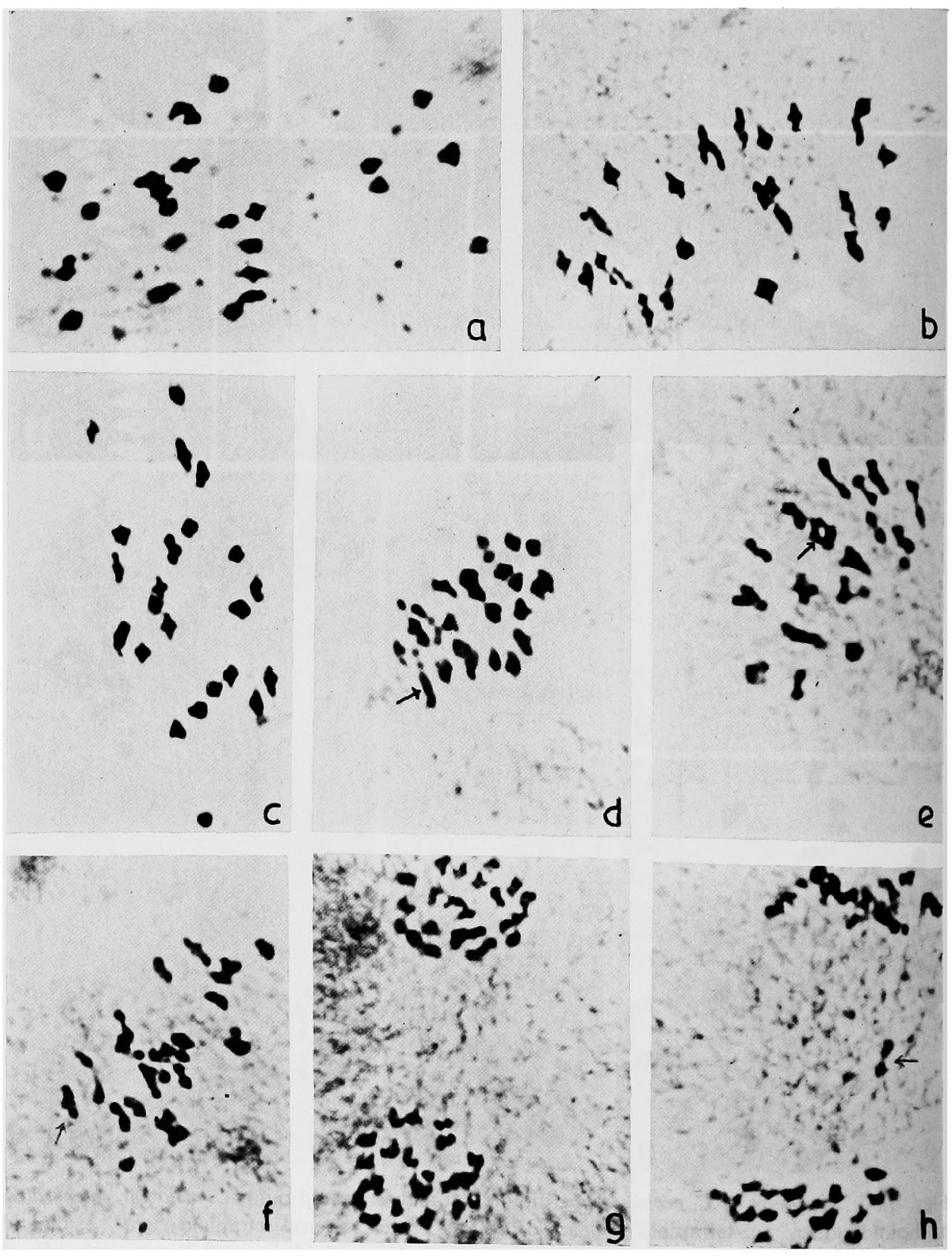

Figs. 2a-h. Pollen mother cells at MI showing: a, 24 II in C.pustulatus. b, in C. membranifolius. c, in C. meeusei. d, $24 \mathrm{II}+1 \mathrm{IV}$ in $C$. meeusei and $C$. heptadactylis. e, $\mathrm{f}$ in PMC at AI showing $\mathrm{g}$, unequal distribution. $\mathrm{h}$, laggards. $\times 1200$. 
and unequal distribution (Figs. $2 \mathrm{~g}, \mathrm{~h}$ ), and little lower pollen fertility $(52 \%$ and $62 \%$, respectively, Table 5).

\section{Discussion}

In Cucumis, reports of natural polyploids by Shimotsuma (1965) and Dane and Tsuchiya (1979) and induction of polyploid with increased fruit size in some wild and semicultivated species by Singh and Roy (1975) have raised new interest. A comparison of meiotic behaviour of colchiploids and natural polyploids shall provide an insight into the nature of polyploidy for natural polyploids and into future cytological, biological and agronomic stability of colchiploids.

Table 5. Chromosome distribution and pollen fertility in induced and natural polyploids of Cucumis

\begin{tabular}{lcccc}
\hline \multicolumn{1}{c}{ Species } & $\begin{array}{c}\text { \% of cells with } \\
\text { normal } \\
\text { distribution }\end{array}$ & $\begin{array}{c}\% \text { of cells } \\
\text { with unequal } \\
\text { distribution }\end{array}$ & $\begin{array}{c}\% \text { of cells with } \\
\text { laggards }\end{array}$ & $\begin{array}{c}\% \text { Pollen } \\
\text { fertility }\end{array}$ \\
\hline Natural polyploids & 100 & 0 & 0 & 75 \\
C. pustulatus & 100 & 0 & 0 & 78 \\
$\begin{array}{l}\text { C. membranifolius } \\
\text { C. heptadactylis }\end{array}$ & 80 & 15 & 5 & 60 \\
C. meeusei & 70 & 20 & 10 & 52 \\
Colchiploids & & & & \\
C. melo var. momordica & 50 & 20 & 30 & 77.7 \\
C. prophetarum & 48 & 22 & 30 & 76.7 \\
\hline
\end{tabular}

In general, induction of polyploidy increases the cell size (Stebbins 1950), which in turn provides gigantism to the plants over their diploids. In cucurbits it has not been a universal feature especially in relation to fruit character. Earlier reports of Shifriss (1942) indicated that initial increase in size of ovary does not keep pace with further development of plant, thus resulting in small fruits. But in the present investigation, contrary to earlier reports, in both the taxa, the plants with increased ploidy showed vigour after initial stunted growth and later attained a near normal growth producing vigorous plants. The initial increase in the ovary size of female flowers in the present material kept pace with the further development of plants resulting in comparatively larger fruits; the seed size also increased although the number of fruits per plant and the number of seeds per fruit were quite low (Table 3), which is not unexpected keeping in view the new genetic constitution of these autopolyploids, which result in meiotic and physiological instability. However this vigour and prolonged duration of these autotetraploids, if consistently observed in later generations can be exploited for getting fruits over the normal season. These observations reinforce the earlier observations of Singh and Roy (1975) that in wild and semicultivated taxa which have not undergone heavy selection pressure, the polyploid breeding still stands with hope.

In both the autotetraploids a high frequency of bivalents has been recorded, so much so that a high percentage of cells has only bivalents. There can be various 
reasons for such a cytological behaviour in a raw autotetraploid. In Cucumis species small size and high number of submedian and acrocentric chromosomes can result in reduction of chiasma frequency and/or in their localization which can result in breakdown of a multivalent into bivalents at an early stage of meiotic cycle. Moreover in a raw autotetraploid, chiasma frequency can get reduced because of genetic imbalance and mechanical interference for the availability of partner exchange at the pairing initiation site, which may attract different partners at the same time. John and Henderson (1962) have also observed bivalent formation in autotetraploids with small chromosomes. The other possibility for high bivalent frequency may be genetic control of pairing which requires further investigations.

The natural polyploids also had a very high bivalent frequency, so much so that in C. membranifolius and C. pustulatus only regular bivalents were ovserved, which is indicative of allopolyploid nature of these two species. High pollen fertiliy of these taxa further strengthens this conclusion. But regular bivalent formation can be observed even in autotetraploid as a consequence of attainment of diplontic behaviour or on account of genetic control of pairing. Hence conclusive evidence on nature of polypoidy in these taxa can be obtained from crossing of these taxa with ancestral diploid taxa, as has already been evidenced in case of $C$. pustulatus by Dane et al. (1980), or through evidences from other lines of investigations.

In two other natural polyploid species $C$. heptadactylis and C. meeusei, the recorded multivalent associations are indicative of their autopolyploid nature. Though such a frequency of multivalents can also be possible in segmental allopolyploids but the comparable multivalent frequency observed in artificial autotetraploids studied in present investigation reinforce the autotetraploid nature of these two species. Earlier Shimotsuma (1965) and Dane and Tsuchiya (1979) in C. heptadactylis observed a higher frequency of multivalents than observed in present investigation. This suggests that presently observed low frequency of multivalents in these taxa is due to the progressive attainment of diplontic behaviour in subsequent generations. Probably, either selection of desirable mutant ensuring bivalent formation, or zygote resulting from fusion of gametes from PMCs with regular bivalents has conferred upon the tetraploids the advantage for the progression to diplontic nature. The low pollen fertility observed in these two natural polypoid species compared to the two preceding polyploid taxa suggest that multivalent formation leads to irregular distribution of chromosomes, and lowers the pollen fertility. A comparable situation in the colchiploids studied in present investigation further suggests that they can also regain diplontic behaviour and fertility with preferential selection of diplontic gametes in subsequent generations.

The seed fertility in the induced autoteraploids, even with a high pollen fertility, was very poor which is suggestive of the fact that for seed fertility the normal meiotic cycle at gametic level is not the only prerequisite, and it is affected by some other factor as well, such as genetic or physiological.

In $\mathrm{C}_{2}$ generation $20-25 \%$ of the plants breed true for their ploidy level which can be differentiated morphologically from their diploid counterparts on account of the vigour. Reversion of a majority of the progenies to the diploid level indicates that monoploid gametes compete better than diploid, on account of their prolonged 
genetic stability in nature. Subsequent selection of polyploid progenies may result in stable tetraploidy.

The present observations supporting earlier reports of Roy and Ghosh (1971) and Singh and Roy (1975) indicate a happy situation for polyploid breeding in wild and semicultivated cucurbitaceous taxa. Though conclusive evidences can be obtained by the detailed biological and agronomic assessment of these autotetraploids in subsequent generations, but the comparable observations in natural autotetraploids studied here strongly suggest that through generation advance they should regain diplontic behaviour to result in normal meiotic cycle and fertility keeping the desired features of higher ploidy, as observed in C. vulgaris(Andrus et al. 1971).

From the basic point of view, the observations in natural polyploid taxa suggest that polyploidy either independently or in combination with hybridization has evolved new population in the genus Cucumis. It should be pointed out that all the species recorded with polyploid number so far are perennials. Therefore in nature the process of polyploidy has been successful in species, where perenniality of a taxa can sustain either autotetraploidy or a sterile hybrid for a longer period to achieve spontaneous doubling of chromosomes, and produce allopolyploid to resort back to sexual mode of reproduction.

\section{Summary}

Colchiploids were raised in C. melo var. momordica and C. prophetarum. Morphologically autotetraploids were vigorous with a little increase in fruit size, though with decrease in number of fruits per vine and seeds per fruit.

A comparative meiotic analysis of colchiploids and four natural polyploids, C. pustulatus, C. membranifolius, C. meeusei and C. heptadactylis revealed that C. pustulatus and $C$. membranifolius with regular bivalent assoication are allopolyploids, while $C$. meeusei and $C$. heptadactylis with a few multivalent assoications are autopolyploids, may be segmental allopolyploids. A higher frequency of bivalents in C. heptadactylis compared to earlier reports suggests that either selection of mutants ensuring bivalent association or diplontic gametes are evolving these species to diplontic behaviour. A high bivalent frequency comparative to natural polyploids observed in colchiploids suggest that they can attain diplontic behaviour like natural polyploids with generation advance and later may stabilise cytologically, sexually and agronomically.

\section{References}

Andrus, C. F., Seshadri, V. S. and Grimball, P. C. 1971. Production of seedless watermelons. Technical Bull. No. 1425, USDA, 1-12.

Agrawal, P. K. and Roy, R. P. 1976. Natural polyploids in Cucurbitaceae I. Cytological studies in triploids Momordica dioica Roxb. Caryologia 29: 7-13.

Celarier, R. P. 1956. Tertiary butyl alcohol dehydration of chromosome smears. Stain Technol. 31: $155-157$.

Dane, F. and Tsuchiya, T. 1979. Meiotic chromosomes and pollen morphological studies of polyploid Cucumis species. Euphytica 28: 563-567.

-, Denna, D. W. and Tsuchiya, T. 1980. Evolutionary studies of wild species in the genus 
Cucumis. Z. Pflanzenzüchtg. 85: 89-100.

Jackson, R. C. 1976. Evolution and systematic significance of polyploidy. Ann. Rev. Ecol. Syst. 7: 209-234.

John, B. and Henderson, S. A. 1962. Asynapsis and polyploidy in Schistocerca paranensis. Chromosoma 13: 111-147.

Kihara, H. 1951. Triploid watermelons. Proc. Amer. Soc. Hort. Sci. 58: 217-230.

Müntzing, A. 1951. Cytogenetic properties and practical value of tetraploid rye. Hereditas 37: 17-84.

Randolf, L.F. 1932. Some effects of high temperature on polyploidy and other variation in maize. Proc. Nat. Acad. Sci., USA 18 : 222-229.

Roy, R. P., Thakur, V. and Trivedi, R. N. 1966. Cytogenetical studies in Momordica L. J. Cytol. Genet. 1: 30-40.

- and Ghosh, J. 1971. Experimental polyploids of Luffa echinata Roxb. Nucleus 14: 111-118.

Shifriss, O. 1942. Polyploids in genus Cucumis L. J. Hered. 33: 144-152.

Shimotsuma, M. 1965. Chromosome studies of some Cucumis species. Seiken Ziho 17: 11-16.

Singh, A. K. 1974 . Cytological studies in Melothria (Linn.) Ann. of Arid Zone Res. 13: 266-268.

- 1979. Cucurbitaceae and polyploidy. Cytologia 44: 897-905.

- and Roy, R. P. 1975. Studies on the colchiploids of Cucumis melo L. Nucleus 18: $39-43$.

- and - 1979. Cytological studies in Trichosanthes L. J. Cytol. Genet. 14: 50-51.

Stebbins, G. L. 1950. Variation and Evolution in Plants. New York: Columbia Univ. Press.

- 1971. Chromosomal Evolution in Higher Plants. London: Edward Arnold. 